\title{
Economic Dispatch of Hydrogen Systems in Energy Spot Markets
}

\author{
Shi You and Per Bromand Nørgård
}

\begin{abstract}
Hydrogen system, as a new energy carrier, could deliver clean and efficient energy services in a wide range of applications. This paper presents an economic dispatch-based mathematical model that facilitates investigations on the techno-economic feasibility of hydrogen systems in the context of energy spot markets. The generic hydrogen system is comprised of an electrolysis for hydrogen production, a hydrogen storage tank and a fuel cell system for cogeneration of electricity and heat. A case study is presented with information from practical hydrogen systems and the Nordic energy markets to demonstrate the effectiveness of the proposed model and approach.
\end{abstract}

Index Terms-Economic dispatch, energy market, hydrogen system, techno-economic feasibility.

\section{INTRODUCTION}

The growing need for the development of sustainable energy systems call for new forms of energy carriers. Although many alternative sustainable energy pathways have been proposed, the so-called "hydrogen economy" has received particular attention in the past decade [1]-[3]. In hydrogen economy, hydrogen is utilized as a viable and advantageous energy carrier option for delivering clean and efficient energy services in a wide range of applications. Another focus of hydrogen economy is on creating the synergies between different energy systems by developing a hydrogen-enabled integrated energy system solution. With this solution, the flexibility of each energy system can be utilized in an optimal and synthetic manner [4]. The challenges faced by each energy system, such as renewable integration in the electrical grid, can therefore be addressed properly under an integrated perspective.

Many investigations on hydrogen economy primarily focus on how to realize, improve and take advantage of the bidirectional conversation feature between electricity and hydrogen, as depicted in Fig. 1. With technology that is available today, this closed loop operation converts electricity into hydrogen by electrolysis, and re-electrifies the hydrogen using various fuel cell technologies. The round trip efficiency today is as low as 30 to $40 \%$ [5], disregarding the possibility of cogeneration if heat produced during the process, such as by fuel cells, can be captured for use. Despite this low efficiency, the interest of using this kind of hydrogen energy

Manuscript received November 20, 2014; revised April 21, 2015. This work was supported in part by the Danish Energy technology development and demonstration funding program.

The authors are with the Center for Electric Power and Energy, Department of Electrical Engineering, Technical University of Denmark, Elektrovej 325, Lyngby, DK 2800, Denmark (e-mail: sy@elektro.dtu.dk, pern@elektro.dtu.dk). storage alternative keeps growing. The first full-scale hydrogen-powered community of EU demonstrated in Lolland, Denmark presents a showcase example of this hydrogen-based solution [6]. In this application, excess wind power is converted to hydrogen via centralized production and stored in low pressure tanks. Through a number of installations of domestic fuel cell micro-CHPs, the need for heat and electricity from each household is met individually, resulting 100\% carbon neutral. Other applications for utilizing this kind of hydrogen solution to facilitate renewable integration are given by [7], [8]. The installed capacity of these real-life applications are typically below $100 \mathrm{~kW}$.

However, in an energy system with high share of renewables, the energy price, especially the electricity price, can be dramatically affected by the production from renewables such as wind [9], [10], which may to a great extent affect the operational economy of different hydrogen-based applications. For countries like Denmark that aims for $100 \%$ renewable with $50 \%$ electricity produced by wind [11], such kind of analysis must consider the energy price volatility. The presented study intends to facilitate the techno-economic feasibility analysis for hydrogen systems as described in Fig. 1 by proposing an economic dispatch-based mathematical modelling approach. A case study is presented in the end with information collected from practical hydrogen systems and the Nordic energy markets to demonstrate the effectiveness of the proposed approach.

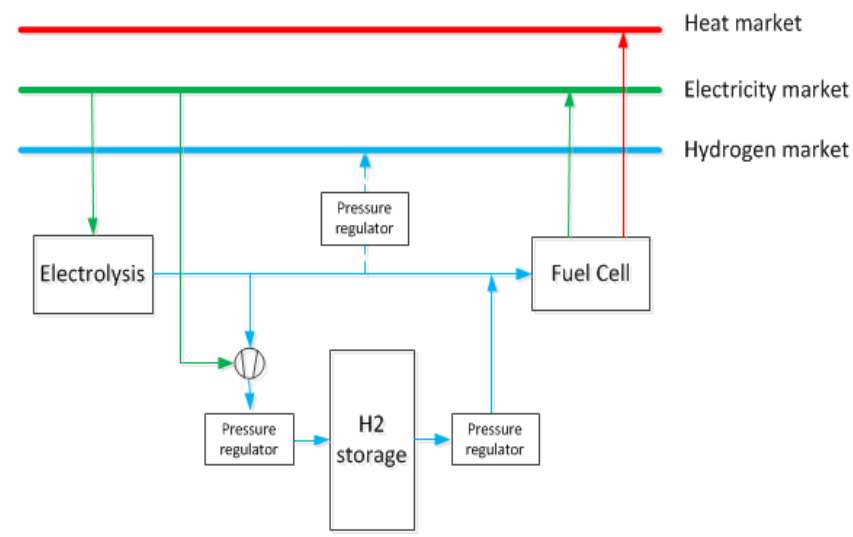

Fig. 1. Schematic description a generic hydrogen system in energy markets.

\section{MATHEMATICAL FORMULATION}

Economic dispatch is classically a short-term scheduling (i.e. usually on daily basis) of the optimal output of a number of controllable facilities to achieve the lowest possible cost/the highest profit, while considering forecasts, operational constraints, etc. In this study, the objective of the economic dispatch formulation of the generic hydrogen 
system is to minimize the total cost for one optimization period with $T$ time intervals by determining the energy exchange between the hydrogen systems and the external grids/markets, while considering the variation between different operation modes that is usually considered only in unit commitment problems.

$$
\min \sum_{t=1}^{T} \sum_{k \in K} \sum_{j \in J}\left(\lambda_{k, t} \cdot P_{k, t}^{j} \cdot u_{t}^{j}\right)
$$

wherein

$K=\left\{e l, h_{2}, t h\right\}$ represents a set of the three energy forms electricity, hydrogen and heat;

$J=\{E L, H S, F C\}$ represents a set of the three subsystems electrolysis, hydrogen storage and fuel cell;

$\lambda_{k, t}$ represents the spot price for different forms of energy at time $t$;

$P_{k, t}^{j}$ represents the energy exchange between each subsystem and the external grids/markets at a single time instant (positive values indicate to buy/flow in and negative values indicate to sell/flow out );

$\boldsymbol{u}_{\boldsymbol{t}}^{j}$ represents the operation mode of each subsystem, can vary between on/off/standby.

The dispatch objective is subject to a number of constraints associated with each subsystem and the overall setup, including

$$
\left\{\begin{array}{l}
g\left(P_{k, t}^{j}, u_{t}^{j}\right)=0 \\
h\left(P_{k, t}^{j}, u_{t}^{j}\right) \leq 0
\end{array}\right.
$$

The equality constraints $g$ includes three forms of balancing equations, i.e.

1) The energy balance in each energy form for the overall system, such as the total electricity exchange between the hydrogen system and the external grid equals to the difference between electricity consumed by power components like electrolysis and the electricity generated by fuel cell;

2) The simultaneous energy conversation for each subsystem, such as the amount of hydrogen produced by the electrolysis at time $t$ equals to the multiply between the amount of electricity consumed by the electrolysis at time $t$ and the conversion efficiency;

3) The difference equation that represents the dynamic characteristics of hydrogen storage tanks.

The inequality constraints $h$ include:

1) The capacity constraints of each subsystem;

2) The constraints defining different operation modes and the transfer state between two neighboring operation modes [12].

\section{CASE STUDY}

\section{A. System Description}

The presented case study is derived from a demo-oriented
R\&D project "Copenhydrogen" [13] that intends to identify the key technical and economic variables that will affect the economic performance of a hydrogen system that was planned for the city of Copenhagen. A mixed integer programming (MIP) model based on the mathematical formulation given earlier is developed to simulate the optimal operation of the Copenhydrogen system. By taking the hourly prices (i.e. price for electricity, heat and hydrogen if relevant) and component parameters as input, the model produces an optimal schedule for each component that results the minimum operation cost of the whole system in the scheduling period. The technical parameters of the hydrogen system are given in Table I.

\begin{tabular}{|c|c|c|c|}
\hline Parameter & $\begin{array}{l}\text { Aklaline } \\
\text { electrolysis (EL) }\end{array}$ & PEMFC (FC) & $\begin{array}{l}\text { Hydroge } \\
\text { n Storage } \\
(\mathrm{HS})\end{array}$ \\
\hline capacity & 25-500 (kW_el) & $\overline{5-50(\mathrm{~kW} \text { _el })}$ & $\begin{array}{l}0-100 \\
\left(\mathrm{~kg} \_\mathrm{H}_{2}\right)\end{array}$ \\
\hline standby & 0.25 (kW_el) & 0.5 (kW_el) & - \\
\hline hot-start & 2.5 (kWh_el) & 1 (kWh_el) & - \\
\hline cold-start & 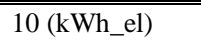 & 4 (kWh_el) & - \\
\hline min-on time & $0(\mathrm{~h})$ & $0(\mathrm{~h})$ & - \\
\hline min-off time & $0(\mathrm{~h})$ & $0(\mathrm{~h})$ & - \\
\hline \multirow{2}{*}{ eff_conversion } & $\begin{array}{l}4.58 \\
\left(\mathrm{kWh} / \mathrm{Nm}^{3}{ }_{2} \mathrm{H}_{2}\right)\end{array}$ & $\begin{array}{l}1.1 \\
\left(\mathrm{kWh} / \mathrm{Nm}^{3} \_\mathrm{el}\right) \\
\end{array}$ & - \\
\hline & $\begin{array}{l}8.99 \\
\left(\mathrm{kWh} / \mathrm{Nm}^{3}{ }_{2} \mathrm{O}_{2}\right)\end{array}$ & $\begin{array}{l}2.2 \\
(\mathrm{kWh} / \mathrm{Nm} 3 \text { th) }\end{array}$ & - \\
\hline eff_compressor & - & - & $\begin{array}{l}0.449 \\
(\mathrm{~kg} / \mathrm{kWh}) \\
\end{array}$ \\
\hline inlet/outlet flow & - & - & $0-10(\mathrm{~kg})$ \\
\hline
\end{tabular}

TABLE I: TECHNICAL PARAMETERS OF THE COPENHYDROGEN SYSTEM

In addition to the technical information given in Table I, some assumptions have been made to facilitate the model development:

1) For electrolysis and fuel cell, hot start-up is defined as a state-shift from standby-state to on-state; cold start-up is defined as a state-shift from off-state to on-state.

2) For electrolysis and fuel cell, the allowed operational mode include: on to off, on to standby, on to on, standby to on, standby to standby, off to off, and off to on.

3) For electrolysis and fuel cell, start-up time is disregarded. This is due to the fact both cold start-up and hot start-up for the selected components can be done within less than 10 minutes. However, start-up costs (i.e. measured by the amount of electricity consumed for start-up) of cold-start and hot-start are included to indicate the difference between the two start-up modes.

4) The capacity of hydrogen storage is assumed to be 10 times of the production capacity of the electrolysis.

5) The minimum-on and minimum-off time of the electrolysis and the fuel cell are included in the model, but not applied in the simulation due to fact the practical values are relatively small.

\section{B. Simulation Scenarios}

By briefly analyzing the weekly behavior of wind power and electricity spot prices (i.e. measured on hourly basis) of year 2012 for DK2 (as illustrated by Fig. 2), three price scenarios wherein each includes hourly data collected over a week, were selected to represent different possible situations for the electricity spot market in east Denmark. Each situation 
to some extent reflects how the wind power impacts the electricity spot price. For instance for scenario 3, i.e. week 52, the spot price of electricity during that week has low average price along with large variation, while the corresponding wind power profile has a high average power with a relatively large variation. The hourly electricity prices of the selected weeks are served as input to the economic dispatch model developed for the Copenhydrogen system. For all simulations, prices of the hydrogen and the heat are assumed to be fixed at $15 \mathrm{DKK} / \mathrm{kg}$ and $0.3 \mathrm{DKK} / \mathrm{kWh}$ respectively.

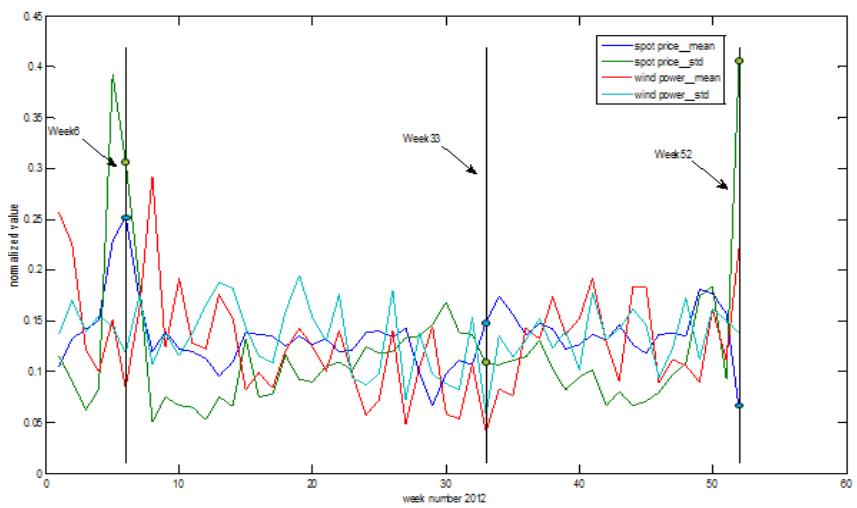

Fig. 2. Scenarios of the electricity spot prices selected in 2012 for simulation.

\section{Simulation Results}

As an example of showing the simulation results of each scenario, Fig. 3 illustrates the hourly performance of each subsystem of the hydrogen system and the energy price variation in the context of scenario 1. As for the corresponding economic performance of this scenario, it sums the daily cost/profit of the Copenhydrogen system (i.e., calculated on hourly basis according to the mathematical formulation in Section 2) over the simulated one-week period. In the simulated period, the electrolysis works less frequently than the fuel cell, while the hydrogen tank is only completely filled up once.

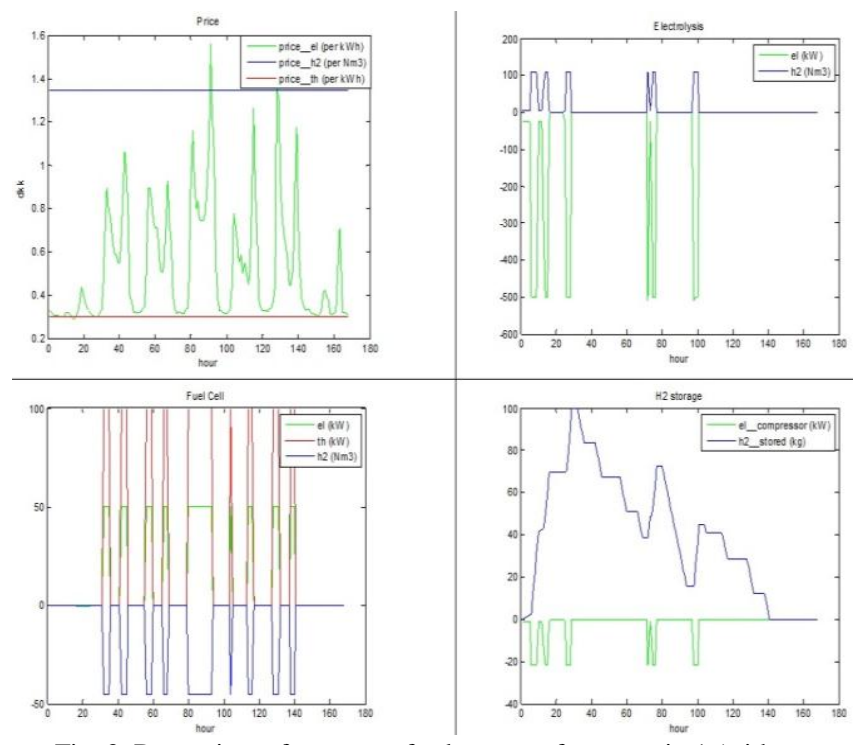

Fig. 3. Dynamic performance of subsystems for scenario 1 (without hydrogen market).

Fig. 4 illustrates the economic performance of the hydrogen system under different price scenarios, also considering the difference between with and without hydrogen market.

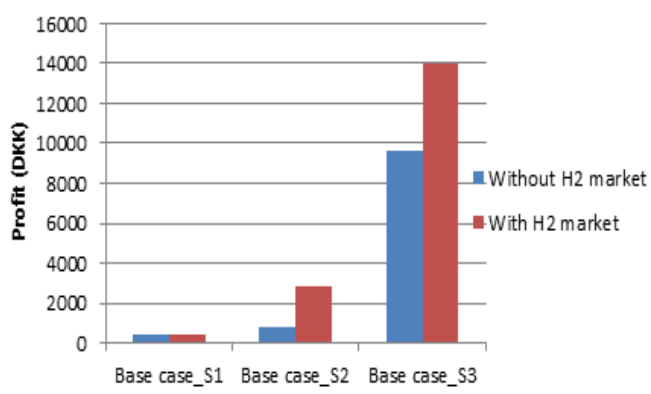

Fig. 4. Comparison of the economic performance of the hydrogen system under different simulation scenarios.

As a result, it can be found

- The enabling of hydrogen market has a strong positive impact on the economic performance of the hydrogen system.

- For scenario 1, i.e., week 6 which has a high average electricity prices $525.383 \mathrm{DKK} / \mathrm{MWh}$ and also a high price variation measured by the standard deviation 264.749DKK/MWh, the benefit collected over that week for the hydrogen system is quite low.

- For scenario 2, i.e., week 33 which has a medium level average price 309.542DKK/MWh and also a medium level price variation $92.975 \mathrm{DKK} / \mathrm{MWh}$, the profit achieved over the week for the hydrogen system is around two times the profit collected in scenario 1 when hydrogen market is disenabled.

- For scenario 3, i.e., week 52 which has a low average price of $129.118 \mathrm{DKK} / \mathrm{MWh}$ and a relatively high price variation $354.978 \mathrm{DKK} / \mathrm{MWh}$, the profit achieved over this simulated period is 10 times more than scenario 1 .

- Market conditions with low averaged electricity price and high price variability offers the hydrogen system better margin opportunities through arbitrage.

\section{CONCLUSIONS}

Hydrogen systems represent a promising solution to support the development of a clean energy-based sustainable society. The study proposed a mathematical modeling approach that facilitates the techno-economic feasibility analysis of hydrogen systems in the context of energy spot markets. A case study with practical information collected from the Danish Copenhydrogen project was performed to illustrate the proposed approach. The proposed models can also be used for techno-economic sensitivity analysis when design/size different hydrogen system applications.

\section{REFERENCES}

[1] L. Barreto and A. Makihira, "The hydrogen economy in the 21st century: A sustainable development scenario," International Journal of Hydrogen Energy, vol. 28, issue 3, pp. 267-284, 2003.

[2] G. Marbán and V. S. Teresa, "Towards the hydrogen economy?" International Journal of Hydrogen Energy, vol. 32, issue 12, pp. 1625-1637, 2007.

[3] W. G. Raphael and A. Rastetter, "Power to gas: The final Breakthrough for the hydrogen economy?" Green, vol. 3, issue 1, pp. 69-78, 2013.

[4] P. Mancarella, "MES (multi-energy systems): An overview of concepts and evaluation models," Energy, vol. 65, pp. 1-17, 2014. 
[5] P. Medina, A. W. Bizuayehu, J. P. Catalão, E. M. G. Rodrigues, and Contreras, "Electrical energy storage systems: Technologies' state-of-the-art, techno-economic benefits and applications analysis," in Proc. 47th Hawaii International Conference on System Sciences (HICSS), 2014, pp. 2295-2304

[6] S. Magnoni and A. M. Bassi, "Creating synergies from renewable energy investments, a community success story from Lolland, Denmark," Energies, vol. 2, issue 4, pp. 1151-1169, 2009.

[7] K. W. Harrison et al., "The wind-to-hydrogen project: Operational experience, performance testing, and systems integration," Technical Report No.: NREL/TP55044082, National Renewable Energy Laboratory, pp. 200-211, 2009.

[8] Ø. Ulleberg, N. Torgeir, and A. Ete, "The wind/hydrogen demonstration system at Utsira in Norway: Evaluation of system performance using operational data and updated hydrogen energy system modeling tools," International Journal of Hydrogen Energy, vol. 35, issue 5, pp. 1841-1852, 2010.

[9] C. K. Woo, I. Horowitz, J. Moore, and A. Pacheco, "The impact of wind generation on the electricity spot-market price level and variance: The Texas experience," Energy Policy, vol. 39, issue 7, pp. 3939-3944, 2011.

[10] M. Nicolosi, "Wind power integration and power system flexibility An empirical analysis of extreme events in Germany under the new negative price regime," Energy Policy, vol. 38, issue 11, pp. 7257-7268, 2010.

[11] H. Lund, and B. V. Mathiesen, "Energy system analysis of $100 \%$ renewable energy systems - The case of Denmark in years 2030 and 2050," Energy, vol. 34, issue 5, pp. 524-531, 2009.

[12] P. Martens, E. Delarue, and W. Dhaeseleer, "A mixed integer linear programming model for a pulverized coal plant with post-combustion carbon capture," IEEE Transactions on Power Systems, vol. 27, issue 2, pp. 741-751, 2012.

[13] CopenHydrogen homepage. [Online]. Available: http://www.hydrogennet.dk/copenhydrogen/

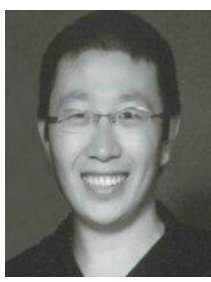

Shi You was born in 1981 in China. He is currently a research scientist with the Center for Electric Power and Energy, Department of Electrical Engineering, Technical University of Denmark. He received his $\mathrm{PhD}$ and $\mathrm{MSc}$ degrees in electrical engineering from Technical University of Denmark and Chalmers Institute of Technology, Sweden in 2010 and 2007, respectively.

He has gained enormous research and development experience in the field of smart grid from participating several Danish EU-wide and international projects. His research focuses on enabling a seamless integration of distributed energy resources into the distribution systems from various aspects, i.e. information and communication technology (ICT), power system operation and control and electricity markets. Dr. Shi is also a member of IEEE.

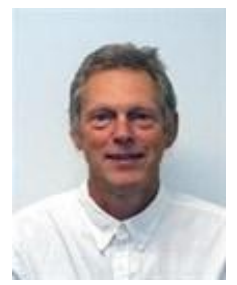

Per Bromand Nørgård was born in 1951. He is currently a senior development engineer with the Center for Electric Power and Energy, Department of Electrical Engineering, Technical University of Denmark. He received his MSc degree in electrical engineering from Technical University of Denmark in 1976. His expertise covers integration of wind power in power system, smart grid, smart energy systems and smart cities. 
Bioenergy 
